\title{
FENOMENA PILGUB BABEL 2017 \\ (MEMAHAMI KARAKTER PEMILIH PEMULA DALAM MENENTUKAN HAK KONSTITUSIONALNYA)
}

Oleh:

\author{
Rio Armanda Agustian, S.H., M.H. ' dan \\ Abdul Rasyid Saliman bin Mohd. Arsyad Midin *** \\ Email: rioarmanda.agustian@yahoo.com
}

\begin{abstract}
This study discusses the phenomenon of Babel Pilgub 2017 in understanding the extent of the character of early voters in determining their constitutional rights in the Pilgub. The novice viewers' views are now evolving and have undergone many changes. The approach model used by the beginner Bangka Beliutng voters in determining and dropping their choice. The advance level of the beginner's education of Bangka Belitung became the main reason for the occurrence of electoral disorientation. So far, the most dominant and decisive primordial factor of primal voters has shifted toward the achievement factor of the candidates. This can be seen from 27,988 novice voters or $3.08 \%$ of the total number of existing voters list, the distribution of candidate achievement relationships with the choice of the novice to the spouse is very strong. The results of this study indicate that there is a tendency to change the character of the beginner voters before they decide and choose their choice to cover five aspects such as the novice voters to choose candidate pairs of governors / representatives who are faithful, honest, rich, fair and able to separate between the people's property and private property, knowing what the advantages and disadvantages of the candidates are, they do not choose candidate pairs who use money politics or any unlawful means to get people to vote for them, and they choose candidate pairs that use the wealth of the people for the importance of education and welfare.
\end{abstract}

Keywords : The phenomenon of Babel Pilgub 2017, constitutional rights, the approach model used by the beginner voters, the character of the beginner voters

\section{A. PENDAHULUAN}

Situasi sosial ekonomi masyarakat Kepulauan Bangka Belitung sangat tergantung dengan komoditas utama hasil perkebunan lada, karet, sawit dan lain-lain serta hasil tambang timah. baik yang dikelola oleh PT. Timah sebagai tambang negara, ${ }^{1}$ maupun tambang yang dikelola oleh perusahaan tambang lainnya, serta tambang rakyat (tambang inkonvensional). Namun demikian, masih banyak

\footnotetext{
*Dosen Tetap Fakultas Hukum Universitas Bangka Belitung.

**Dosen Tetap Fakultas Hukum Universitas Bangka Belitung.

${ }^{1}$ PT. Timah merupakan salah satu Badan Usaha Usaha Milik Negara
} 
lahan-lahan eks tambang-tambang timah tersebut belum dikelola kembali sebagaimana mestinya.

Di bidang perkebunan dan pertanian, hasil perkebunan sawit baik yang dikelola perusahaan sawit nasional maupun perkebunan sawit rakyat merupakan penyokong ekonomi masyarakat yang cukup besar di samping hasil perkebunan rakyat utama lainnya, seperti lada, karet dan lainnya.

Hasil utama pertambangan, pertanian dan perkebunan tersebut selama ini sangat tergantung dengan harga pasar internasional, yang apabila harga mencapai tingkat tertinggi maka masyarakat Bangka Belitung akan menikmati keuntungan dan kesejahteraan yang baik, dan apabila harga komoditas tersebut berada pada tingkat harga rendah, maka masyarakat akan mengalami kondisi kerugian dan kesuraman yang buruk.

Sangat jelas, bahwa fluktuasi harga komoditas utama tersebut sangat berpengaruh buruk terhadap kondisi sosial dan ekonomi masyarakat Bangka Belitung secara keseluruhan. Hal demikian, apabila kerentanan harga komoditas tersebut terus menerus tidak dikelola secara baik akan berakibat semakin tingginya tingkat kriminalitas di bidang ekonomi di kalangan masyarakat pada umumnya, seperti illegal logging, illegal mining dan lain-lain yang akan semakin memperburuk kondisi sosial ekonomi masyarakat.

Oleh karena itu, pengelolaan lahan perkebunan kelapa sawit dengan konsep pemberdayaan masyarakat atau pola kemitraan seputar lahan eks tambang timah dan pengelolaan suatu kawasan hutan terpadu merupakan salah satu cara dalam mengatasi ketergantungan masyarakat dengan komoditas utama di masa yang akan datang.

Di bidang politik, pada Rabu 15 Februari 2017 rakyat Babel telah memilih secara langsung kepala daerah (Gubernur/wakil) untuk yang ketiga kali. KPU Babel telah memilih empat pasangan calon Gubernur/ wakil yang akan dipilih. Yusron/ Yusroni (Dobel Yes), Rustam Efendi/ Irwansyah (Babel Rumah Kite), Hidayat Arsani/ Sukirman (Beriman), dan Erzaldi Rosman Djohan/ Fatah (Berkah) untuk menjadi orang nomor satu di Babel.

Di lihat dari latar belakang pasangan calon Gubernur/ wakil ada yang berlatar belakang militer, birokrat dan politikus. Pasangan 
mana yang di usung partai politik bagi pemilih pemula tidaklah menjadi penting karena untuk menjadi Gubernur/wakil memang tidak sekedar berbekal mau dan mampu tetapi harus dengan pemahaman yang mendalam untuk menjadi pemimpin Babel.

Dipahami, bahwa sangat disayangkan bila biaya yang cukup besar dan telah dikeluarkan ternyata sia-sia, karena rakyat salah dalam memilih, keliru dalam memilih kandidat pada saat pilgub, mengingat tantangan ke depan bagi negeri yang memiliki kekayaan sumber daya alam timah, lada, karet, sawit dan hasil laut ini semakin berat. Pada Tabel 1.1 berikut ini dapat di lihat jumlah daftar pemilih tetap dan pemilih pemula pada Pilgub Babel 2017.

Tabel 1.1:

Jumlah Pemilih dan Pemilih Pemula pada Pilgub 2017 Provinsi Bangka Belitung dari Jumlah Penduduk Prov Babel 2016 berjumlah 1.401 .827 orang

\begin{tabular}{|c|l|c|c|c|}
\hline No & \multicolumn{1}{|c|}{ Kab/Kota } & $\begin{array}{c}\text { Jumlah } \\
\text { Pemilih }\end{array}$ & $\begin{array}{c}\text { Pemilih } \\
\text { Pemula }\end{array}$ & $\%$ \\
\hline 1 & Bangka & 194.038 & 5.704 & 2,94 \\
\hline 2 & Bangka Barat & 123.671 & 4.258 & 3,44 \\
\hline 3 & Bngka Selatan & 129.248 & 3.593 & 2,78 \\
\hline 4 & Bangka Tengah & 121.798 & 3.728 & 3,06 \\
\hline 5 & Belitung & 120.270 & 4.022 & 3,34 \\
\hline 6 & Belitung Timur & 83.737 & 2.635 & 3,15 \\
\hline 7 & Pangkalpinang & 140.556 & 4.048 & 2,88 \\
\hline & Total & $\mathbf{9 2 9 . 5 6 7}$ & $\mathbf{2 7 . 9 8 8}$ & $\mathbf{3 , 0 8}$ \\
\hline
\end{tabular}

Sumber: KPU Provinsi Kep. Babel
Sehubungan dengan itu, artikel ini ingin mengkaji para pemilih pemula yang memiliki hak konstitusional pertama kali dapat menggunakan hak tersebut secara jernih dan cerdas dalam memilih pasangan yang benar-benar selama ini telah berprestasi (merit), memiliki visi ke depan, dapat meningkatkan daya saing daerah (competitive spirit) dan akan bekerja untuk kemajuan dan kesejahteraan negeri Serumpun Sebalai.

Berkaitan dengan hal tersebut di atas, pada penelitian ini penulis tertarik untuk membahas Fenomena Pilgub Babel 2017 dalam memahami bagaimana karakter dan kecenderungan pemilih pemula dalam menentukan hak konstitusionalnya pada Pilgub tersebut.

Berdasarkan uraian tersebut di atas, maka dapat dirumuskan pokok permasalahan, sebagai berikut:

1. Bagaimanakah memahami karakter pemilih pemula dalam menentukan hak konstitusionalnya pada Pilgub Babel 2017 tersebut?

2. Apakah faktor primordial pemilih pemula yang paling dominan dan menentukan telah bergeser ke arah faktor prestasi dari para kandidat? 


\section{B. METODE PENELITIAN}

1. Objek dan Lokasi Penelitian

Objek penelitian adalah fenomena Pilgub Babel 2017, sedangkan subjek penelitian adalah memahami karakter pemilih pemula dalam menentukan hak konstitusionalnya dalam Pilgub Babel 2017 dengan tempat penelitian dilaksanakan di Bangka Belitung. Bangka Belitung merupakan provinsi yang sangat kaya akan sumber daya alam yang pada 2017 ini meyelenggarakan pemilihan gubernur/wakil untuk periode 2017-2022.

\section{Tipe dan Pendekatan Penelitian}

Sebagai konsekuensi pemilihan topik permasalahan yang akan dikaji dalam penelitian yang objeknya pemilihan gubernur/wakil Babel, maka tipe penelitian yang digunakan adalah penelitian hukum normatif, yakni penelitian yang difokuskan untuk mengkaji penerapan kaidahkaidah atau norma-norma dalam hukum positif. Dalam hubungan ini, digunakan logika induktif. Logika induktif digunakan untuk menarik kesimpulan dari kasus yang bersifat individual menjadi hal yang bersifat umum ${ }^{2}$. Dalam penelitian ini juga secara proporsional menggunakan penelitian sosiolegal ${ }^{3}$ dan dalam hal ini, digunakan logika deduktif guna menarik kesimpulan dari hal yang bersifat umum ke hal yang bersifat individual ${ }^{4}$.

Dalam kaitannya dengan penelitian normatif disini digunakan beberapa pendekatan, yaitu pendekatan perundangundangan (statute approach). Pendekatan tersebut melakukan pengkajian peraturan perundangundangan yang berhubungan dengan tema sentral penelitian. Selain itu juga digunakan pendekatan perbandingan (comparative approach), dan pendekatan sejarah (historical approach) yang diperlukan guna memperjelas analisis ilmiah yang diperlukan dalam penelitian normatif.

\footnotetext{
${ }^{2}$ Johnny Ibrahim, Teori dan Metodologi Penelitian Hukum Normatif, Bayumedia Publishing, Malang, 2006, hlm. 242.

${ }^{3}$ Adriaan Bedner, Administrative Courts in Indonesia, A Socio-Legal Study, Kluwer Law International, The Hague-Netherland, 2001, hlm. 9.

${ }^{4}$ Anwarul Yaqin, Legal Research and Writing, Lexis Nexis Malaysia Sdn. Bhd, Selangor DE, 2007, hlm. 10.
} 
3. Prosedur Pengolahan Bahan Hukum

Untuk memperoleh bahan penelitian dilakukan dengan prosedur pengumpulan melalui dua cara, yakni: Pertama, studi kepustakaan, studi kepustakaan tidak saja terhadap bahan-bahan perundangan, penulis juga mencari bahan pada buku-buku, jurnal-jurnal, makalah-makalah, laporan-laporan, hasil penelitian, bahan-bahan yang diperoleh dari internet dan keputusan-keputusan pengadilan terdahulu yang berhubungan dengan masalah pilkada di Indonesia.

Jenis bahan yang digunakan dalam penelitian ini, yakni; jenis bahan primer dan bahan sekunder. Jenis bahan primer, yakni jenis bahan yang di dapat berdasarkan hasil di lapangan dengan wawancara dan sifatnya sebagai pelengkap (komplementer), sedangkan jenis bahan sekunder merupakan jenis bahan yang di dapat bukan dari lapangan dan di dapat dalam bentuk tiga bahan hukum, yakni;

a. Bahan hukum primer, yaitu bahan-bahan hukum yang formal, yakni peraturan perundang-undangan yang berhubungan dengan pemilihan kepala daerah.

b. Bahan hukum sekunder, yaitu bahan hukum yang terdiri atas buku-buku teks (textbooks) yang ditulis para ahli hukum yang berpengaruh, jurnaljurnal hukum, pendapat para sarjana, kasus-kasus hukum, yurisprudensi, dan hasil-hasil simposium mutakhir yang berkaitan dengan topik penelitian.

c. Bahan-bahan tersier, yaitu bahan yang memberikan petunjuk maupun penjelasan terhadap bahan hukum primer dan sekunder, seperti; kamus, ensiklopedi dan lain-lain.

Setelah prosedur pengumpulan bahan hukum primer, bahan hukum sekunder, dan bahan-bahan tersier dilakukan, kemudian bahan hukum tersebut diinventarisasi dan diklasifikasi dengan menyesuaikan dengan masalah yang dibahas. Bahan hukum yang berhubungan dengan masalah yang dibahas dipaparkan, disistematisasi, kemudian dianalisis untuk menginterpretasikan hukum yang berlaku. 
4. Pengolahan dan Analisis Bahan Hukum

Adapun bahan-bahan hukum yang telah diperoleh dalam penelitian kepustakaan, aturan perundang-undangan, dan artikel dimaksud penulis uraikan dan hubungkan sedemikian rupa, sehingga disajikan dalam penulisan yang lebih sistematis untuk menjawab isu hukum yang telah dirumuskan dalam rumusan masalah. Bahwa cara pengolahan bahan hukum dilakukan secara induktif yakni menarik kesimpulan dari permasalahan konkrit yang dihadapi terhadap suatu permasalahan yang bersifat umum dan logika deduktif guna menarik kesimpulan dari hal yang bersifat umum ke hal yang bersifat individual. Selanjutnya bahan hukum yang ada dianalisis untuk melihat bentuk sejauh mana kecenderungan pemilih pemula dalam menentukan pilihannya pada Pilgub tersebut sehingga dapat membantu sebagai dasar acuan dan pertimbangan hukum yang berguna secara tepat.

\section{PEMBAHASAN}

\section{Fenomena Pilgub Babel saat ini}

Pemilu memiliki hubungan yang erat dengan negara demokrasi dan negara hukum. Inti dari demokrasi adalah pelibatan rakyat dalam pembentukan dan penyelenggaraan pemerintahan melalui partisipasi, representasi, dan pengawasan, karena salah satu ciri dari demokrasi adalah pemerintah harus bertanggungjawab kepada yang diperintah, pemerintah harus dipilih oleh yang diperintah atau setidak-tidaknya oleh wakil dari yang diperintah. ${ }^{5}$

Di daerah, penguatan DPRD ternyata tidak serta merta mampu mempercepat proses demokratisasi. Munculnya kerangka kelembagaan baru dengan adanya pemilihan kepala daerah secara langsung, sebenarnya diharapkan bisa mereduksi secara luas adanya pembajakan kekuasaan yang dilakukan partai-partai politik yang memiliki kursi di DPRD. Di samping itu, pilgub secara langsung diharapkan juga bisa menghasilkan gubernur yang memiliki akuntabilitas yang lebih tinggi kepada rakyat. ${ }^{6}$

\footnotetext{
${ }^{5}$ Janedjri M.Ghaffar, Demokrasi dan Pemilu di Indonesia, Konstitusi Press (Konpress), Jakarta, 2013, hlm. 183.

${ }^{6}$ Kacung Marijan, Sistem Politik Indonesia (konsolidasi Demokrasi Pasca Orde Baru), Prenada Media, Jakarta, 2012, hlm. 183.
} 
Memilih pasangan Gubernur/ wakil bagi pemilih pemula dengan pendekatan prestasi menjadi simpul kesadaran baru yang terpancar dari keinginan pemilih pemula Babel dalam memilih siapa calon pemimpin mereka saat ini, pemimpin yang berorientasi prestasi pasti memiliki ciri-ciri berkarakter tangguh, pemimpin yang berjiwa seni mengelola, pemimpin dengan keunggulan khas, dapat diandalkan dan memiliki daya tahan dalam kesulitan dan persaingan.

Adapun ciri-ciri pemimpin dengan karakter meritokrasi tersebut adalah: pertama, pemimpin yang berorientasi meritokrasi dapat menghilangkan diskriminasi dan prasangka kesukuan, agama, ras, kedaerahan dan antargolongan, ingat ketika kita berbicara prestasi sekatsekat tersebut menjadi kabur dan memang itu yang diperlukan dan diinginkan masyarakat Babel sekarang dengan model keragaman demografi multi etnik tersebut. Sebenarnya, modal dasar ini sangat kuat. Dimana masyarakat Babel sangat egaliter, santun dan toleran.

Kedua, memiliki visi ke depan dalam membangun daerah, dapat memaksimalkan setiap keunggulan SDA dan SDM daerah dan dapat

memanfaatkan setiap peluang yang ada, dan dapat mengatasi setiap kekurangan serta dapat mengatasi setiap ancaman yang ada, dan cepat menganalisis setiap perubahan yang terjadi dan mampu mengambil keputusan secara tepat, pemimpin yang memiliki sense of crisis.

Ketiga, dapat meningkatkan daya saing daerah, ingat geoekonomi Babel terletak pada posisi yang sangat strategis wilayah pembangunan segitiga SIBABA (Singapura, Batam dan Babel). Penulis meyakini di masa yang akan datang wilayah SIBABA ini akan menjadi titik simpul pusat perputaran (concentric circle) modal yang besar di Asia Tenggara bahkan Asia Pasifik, dimana Babel dapat menjadi pemain dan bukan hanya objek semata dari perputaran tersebut, memilih pemimpin yang memiliki karakter dan semangat berkompetisi adalah sangat tepat dalam situasi dan kondisi tersebut.

$\begin{aligned} & \text { Keempat, pemimpin yang } \\ & \text { berkarakter meritokrasi } \\ & \text { pemimpin yang lebih banyak } \\ & \text { memberi (berkontribusi) bagi }\end{aligned}$
masyarakat Babel, baik sebelum dan
ketika kelak mereka terpilih,
pemimpin yang antikorupsi,
antikolusi dan antinepotisme.


Pandangan pemilih pemula yang sekarang terus berkembang dan akan mengalami banyak perubahan. Model pendekatan yang di pakai pemilih pemula Babel dalam menentukan dan menjatuhkan pilihannya.

Majunya tingkat pendidikan pemilih pemula Babel menjadi alasan utama terjadinya disorientasi pemilihan. Selama ini faktor primordial pemilih pemula yang paling dominan dan menentukan telah bergeser ke arah faktor prestasi dari para kandidat.

Pada Tabel 1.2 di bawah ini dapat dilihat dari 27.988 pemilih pemula atau 3,08 \% dari jumlah daftar pemilih tetap yang ada, meskipun jumlah tersebut tidak memberikan signifikansi secara keseluruhan tetapi dapat di lihat adanya distribusi antara hubungan prestasi para kandidat dengan penjatuhan pilihan dari pemilih pemula terhadap pasangan yang memiliki prestasi adalah kuat.
Tabel 1.2:

Distribusi Pilihan dari Daftar Pemilih

Pemula berjumlah 27.988 Orang bagi

Empat Calon Gubernur pada Pilgub 2017

Provinsi Bangka Belitung

\begin{tabular}{|c|l|r|r|r|r|r|}
\hline No & $\begin{array}{l}\text { Kabupaten/ } \\
\text { Kota }\end{array}$ & JPP & \multicolumn{1}{c|}{ DY } & \multicolumn{1}{c|}{ BRK } & \multicolumn{1}{c|}{ BI } & BK \\
\hline 1 & Bangka & 5.704 & 1.086 & 1.295 & 1.098 & 2.221 \\
\hline 2 & $\begin{array}{l}\text { Bangka } \\
\text { Barat }\end{array}$ & 4.258 & 811 & 966 & 819 & 1.658 \\
\hline 3 & $\begin{array}{l}\text { Bangka } \\
\text { Selatan }\end{array}$ & 3.593 & 684 & 815 & 691 & 1.399 \\
\hline 4 & $\begin{array}{l}\text { Bangka } \\
\text { Tengah }\end{array}$ & 3.728 & 710 & 846 & 717 & 1.452 \\
\hline 5 & Belitung & 4.022 & 766 & 913 & 774 & 1.566 \\
\hline 6 & $\begin{array}{l}\text { Belitung } \\
\text { Timur }\end{array}$ & 2.635 & 501 & 598 & 507 & 1.026 \\
\hline 7 & $\begin{array}{l}\text { Pangkal } \\
\text { Pinang }\end{array}$ & 4.048 & 771 & 919 & 779 & 1.576 \\
\hline & Total & $\mathbf{7 . 9 8 8}$ & $\mathbf{5 . 3 3 1}$ & $\mathbf{6 . 3 5 6}$ & $\mathbf{5 . 3 8 7}$ & $\mathbf{1 0 . 9 0 1}$ \\
\hline & & $\mathbf{1 9 , 0 5}$ & $\mathbf{2 2 , 7 1}$ & $\mathbf{1 9 , 2 5}$ & $\mathbf{3 8 , 9 5}$ \\
\hline
\end{tabular}

Sumber : KPU Prov. Babel Setelah diolah Kembali

Keterangan:

JPP : Jumlah Pemilih Pemula

DY : Dobel Yes

BRK : Babel Rumah Kite

BI : Beriman

BK : Berkah

\section{Perubahan Karakter Pemilih Pemula Babel}

Pemilihan kepala daerah dan wakil kepala daerah bukan sekedar ajang artifisial dalam mewujudkan kedaulatan rakyat. Pilgub merupakan bagian yang sangat penting dari tranformasi politik menuju konsolidasi demokrasi lokal, yang berujung pada kemampuan membentuk pemerintahan daerah 
yang refresentatif, efektif, pro-publik atau tidak. ${ }^{7}$

Pilgub Babel yang semakin berkualitas tidak hanya peningkatan pengetahuan dan keterampilan aturan dan teknis pelaksanaan pilgub. Kesadaran yang lebih diperlukan adalah kesadaran terhadap makna kedaulatan dan suarayang dimiliki sebagai warga negara serta konsekuensi dari pilihannya. Kesadaran ini juga meliputi nilai dan etika dalam berdemokrasi sehingga tidak akan dapat disuap, menjual suara, ataupun melakukan tindakan lain merusak demokrasi. ${ }^{8}$ Di Bangka Belitung, kesadaran baru tersebut dapat di mulai dari kalangan pemilih pemula.

Terjadinya kecenderungan perubahan karakter pemilih pemula sebelum menentukan dan menjatuhkan pilihannya, dengan ciriciri, antara lain: pertama, pemilih pemula memilih pasangan calon Gubernur/wakil yang beriman, jujur, kaya, adil dan dapat memisahkan antara harta milik rakyat dengan harta

${ }^{7}$ Gamawan Fauzi, dkk., Demokrasi Lokal (Evaluasi Pemilukada di Indonesia), Konstitusi Press (Konpress), Jakarta, 2013, hlm. 207.

${ }^{8}$ Janedri M. Ghaffar, Demokrasi Konstitusional (Praktik Ketatanegaraan Indonesia Setelah Perubahan UUD 945), Konstitusi Press (Konpress), Jakarta, 2013, hlm. 127. milik pribadi, ini sangat penting karena sering terjadi setelah terpilih mereka lupa dan selalu menganggap harta milik rakyat adalah juga harta milik pribadi.

Kedua, sejauh ini pemilih pemula mengetahui apa yang menjadi keunggulan dan kekurangan para kandidat menjadi titik perhatian juga, tentu saja dengan melihat prestasi dan kontribusinya bagi masyarakat Babel berdasarkan kompetensinya selama ini, apakah sebagai seorang militer, birokrat, atau politikus.

Ketiga, pemilih pemula tidak memilih pasangan calon yang menggunakan politik uang atau caracara apapun yang tidak halal agar masyarakat memilih mereka, ingat korupsi, kolusi dan nepotisme (KKN) dimulai dari sini, ketika terjadi persengkongkolan antara para kandidat dengan pemilih.

Keempat, pemilih pemula memilih pasangan calon yang antikorupsi, dan akan lebih banyak menggunakan kekayaan rakyat untuk pendidikan dan kesejahteraan.

Kelima, pemilih pemula pasti menyelidik dulu darimana asal-usul uang yang dipakai ketika mereka berkampanye, lebih baik bila para kandidat secara terbuka bersedia di 
audit kekayaannya, baik sebelum dan setelah menjabat.

Suasana yang sangat kondusif menimbulkan gairah tersendiri bagi masyarakat, partisipasi pemilih pemula menjadi ukuran sukses atau tidaknya bagi KPU Babel dalam menyiapkan segala sesuatunya agar berjalan sesuai dengan yang direncanakan.

Penulis meyakini pemilih pemula Babel yang berbudaya antikekerasan dan terkenal sangat religius memiliki benteng iman yang kuat (sebagai anti bodi) untuk tidak tergoda dengan iming-iming uang dan bertindak anarkis, dan yang paling penting, sebagai pembelajaran politik bagi pemilih pemula diharapkan para kandidat bermain bersih dan fair, tidak melakukan serangan fajar, tidak melakukan kampanye hitam (black campaign), tidak menggunakan politik uang (money politics) yang dapat merusak mental dan perilaku pemilih pemula, tidak memprovokasi massa pendukung untuk berbuat anarkis, siap untuk menang siap pula untuk kalah.

Sekali lagi, memilih figur berdasarkan hati nurani sangat lah penting, akan tetapi memilih berdasarkan prestasi para kandidat adalah lebih penting untuk kepentingan pemilih pemula, masyarakat dan rakyat Babel sendiri dikemudian hari, siapapun yang terpilih kita sambut. Fakta di atas telah membuktikannya, memilih pasangan calon dengan penilaian prestasi bagi pemilih pemula adalah suatu keniscayaan.

\section{PENUTUP}

\section{Kesimpulan}

Pandangan pemilih pemula yang sekarang terus berkembang dan akan mengalami banyak perubahan. Model pendekatan yang di pakai pemilih pemula Babel dalam menentukan dan menjatuhkan pilihannya. Majunya tingkat pendidikan pemilih pemula Babel menjadi alasan utama terjadinya disorientasi pemilihan. Selama ini faktor primordial pemilih pemula yang paling dominan dan menentukan telah bergeser ke arah faktor prestasi dari para kandidat. Ini dapat di lihat dari 27.988 pemilih pemula atau 3,08 \% dari jumlah daftar pemilih tetap yang ada, distribusi hubungan prestasi para kandidat dengan penjatuhan pilihan dari pemilih pemula terhadap pasangan yang selama ini memiliki prestasi adalah kuat. 
Kecenderungan perubahan karakter pemilih pemula sebelum mereka menentukan dan menjatuhkan pilihannya meliputi lima aspek antara lain pemilih pemula memilih pasangan calon Gubernur/wakil yang beriman, jujur, kaya, adil dan dapat memisahkan antara harta milik rakyat dengan harta milik pribadi, pemilih pemula mengetahui apa yang menjadi keunggulan dan kekurangan para kandidat, mereka tidak memilih pasangan calon yang menggunakan politik uang atau cara-cara apapun yang tidak halal agar masyarakat memilih mereka, dan mereka memilih pasangan calon yang banyak menggunakan kekayaan rakyat untuk kepentingn pendidikan dan kesejahteraan.

\section{Saran}

Majunya tingkat pendidikan pemilih pemula Babel menjadi alasan utama terjadinya disorientasi pemilihan, namun demikian pembelajaran politik bagi mereka sangat diperlukan agar terbangun kesadaran baru politik dan budaya politik yang kuat di masa yang akan datang. Partisipasi pemilih pemula pada dasarnya merupakan bagian dari partisipasi pada umumnya.

Keterlibatan pemilih pemula di dalam proses seperti Pilgub Babel 2017 memang lebih banyak berhenti pada proses pemilihan tetapi ketepatan dalam pengambilan keputusan dengan dasar rasionalitas akan berdampak kepada mutu dan kualitas demokrasi itu secara subtantif dan itu akan bermakna untuk membangun demokrasi yang lebih kuat di Babel di masa yang akan datang. Demokrasi yang kuat di Babel akan berdampak pula kepada demokrasi secara nasional.

\section{E. DAFTAR PUSTAKA}

Bedner, Adriaan. 2001. Administrative Courts in Indonesia, A Socio-Legal Study. Kluwer Law International, The Hague-Netherland.

Fauzi, Gamawan, dkk. 2013. Demokrasi Lokal (Evaluasi Pemilukada di Indonesia). Konstitusi Press (Konpress), Jakarta.

Ibrahim, Johnny. 2006. Teori dan Metodologi Penelitian Hukum Normatif. Bayumedia Publishing, Malang.

Marijan, Kacung. 2012. Sistem Politik Indonesia (Konsolidasi Demokrasi Pasca Orde Baru). Prenada Media, Jakarta. 
M.Ghaffar, Janedjri. 2013. Demokrasi dan Pemilu di Indonesia. Konstitusi Press (Konpress), Jakarta.

--------. 2013. Demokrasi Konstitusional (Praktik Ketatanegaraan Indonesia Setelah Perubahan UUD 945). Konstitusi Press (Konpress), Jakarta.

Yaqin, Anwarul. 2007. Legal Research and Writing. Lexis Nexis Malaysia Sdn. Bhd, Selangor DE. 